\title{
A NEW SPECIES OF ARISTELLIGER FROM NAVASSA
}

\author{
Chapman Grant, Major, U. S. Army
}

\section{Aristelliger cochranae sp. nov.}

Type: No. 2320, male, Chapman Grant Collection. 30 May, 1931. Navassa Island; Collector, Crew of L.H.T. "Acacia".

Diagnosis: A gecko of moderate size, the basal half of each digit expanded and provided beneath with unpaired lamellae, the distal half of the larger digits compressed, curved and provided with a claw at the tip; upper side and chin covered with small granules; underside from neck to tip of tail covered with larger imbricated smooth scales. No femoral pores. A distinct black spine on vestiginal eyelid, twice the length of head granules. Body longitudinally striped. Tail cross barred.

Habitat: Navassa Island, off the S W tip of Santo Domingo.

Proportions: Adult, $50 \mathrm{~mm}$. snout to vent. $65 \mathrm{~mm}$. vent to tip of tail. Center of eye slightly in front of center between ear and snout. Ear diamond shaped; as large as first infralabial. Angle of mouth turns up behind eye, then horizontal again. Head broader than neck. Legs short and thick, femoral joint equal to snout to center of eye. Tail round, firm, strong. Eye large, pupil vertical; edges of pupil smooth, not wavy.

Squamation: Rostral deeply creased centrally almost to lip; extends slightly over and laterally on snout. A pair of internasals, separated by one or three scales. Nostril lateral, touching rostral, internasal and postnasal which in turn lies on first supralabial. Ten supralabials; seven and a half to center of eye. Mental, a quadrant. Eight infralabials, first three about half depth of mental. Two postmentals form a right angle inclosing base of mental, followed laterally by two more scales each one half the size of the one preceding. Three or four rows of slightly enlarged, elongated scales border the infralabials. Remainder of throat to neck, covered with small granules. Neck to tip of tail, covered with somewhat larger, smooth, imbricated scales. A barely discernible escutcheon of slightly concave scales anterior to vent of males. All upperside covered with granules, about eleven in diameter of eye. A distinct black spine, occasionally two, on vestiginal eyelid, twice the length of head granules. Legs and feet covered with granules similar to back. The basal half 
of each digit expanded and provided beneath with eight or nine unpaired lamellae forming an oval followed by narrower lamellae to base of digit. The distal half of the larger digits compressed, curved, and provided. with a claw at the tip.

Color and markings: Above, brown; dark stripe bordered with light from snout, crosses eye and runs to shoulder on female and to sacrum on male. Tail bears about nine narrow dark erossbands followed by light bands of the same width, more pronounced on males. Sides marbled. Chin of male marbled; of female white. Belly light or white. Underside tail; female, white; male, dark. Digit pads ash. A regenerated tail is diagonally penciled with jagged lines. Color of young specimen: Snout to vent $20 \mathrm{~mm}$. Beginning at nape, seven light diamonds to sacrum, ten on tail. Dark stripe from snout crosses eye and is then broken outlining diamonds. The young have a decidedly checkered appearance in contrast to the striped adults. The ehange is apparent through medium-sized specimens.

My small series of seven adult to medium sized and six young make it impossible to state definitely whether there is a fixed sexual dichromatism.

Remarks: Named in honor of Doris M. Cochran.

$$
\text { EXPLANATION OF PLATTTE NO. XI.VIII }
$$

Aristelliger cochranae sp. nov.

1. Medium sized male.

2. Adult male. Note full-length stripes.

3. Note pattern of regenerated tail.

4. Adul female. Note stripes stopping at shoulder.

5. Young. Note checkered pattern.

Illustrations life size.

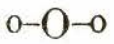




\section{PLATE XLVIII.}

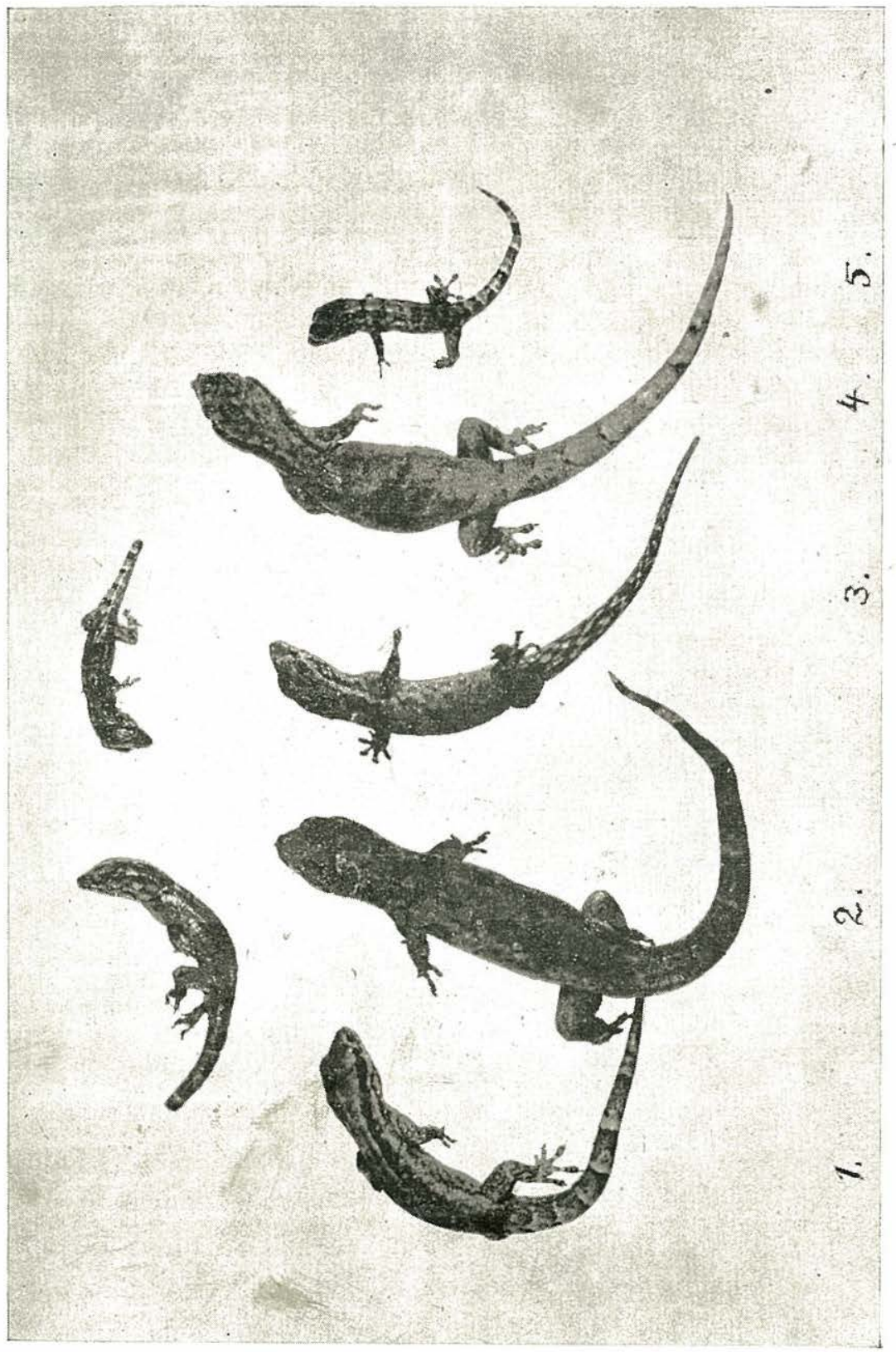

